\title{
Maternal obesity and its effect on labour duration in nulliparous women: a retrospective observational cohort study
}

\author{
Karen Louise Ellekjaer ${ }^{1 *}$ (D) Thomas Bergholt ${ }^{2}$ and Ellen Løkkegaard ${ }^{1}$
}

\begin{abstract}
Background: Obesity is increasing among primipara women. We aimed to describe the association between body mass index (BMI) during early-pregnancy and duration of labour in nulliparous women.

Methods: Retrospective observational cohort study of 1885 nulliparous women with a single cephalic presentation from 37 0/7 to 42 6/7 weeks of completed gestation and spontaneous or induced labour at Nordsjællands Hospital, University of Copenhagen, Denmark, in 2011 and 2012.

Total duration of labour and the first and second stages of labour were compared between early-pregnancy normal-weight (BMl $<25 \mathrm{~kg} / \mathrm{m}^{2}$ ), overweight (BMl $25-29.9 \mathrm{~kg} / \mathrm{m}^{2}$ ), and obese (BMl $\geq 30 \mathrm{~kg} / \mathrm{m}^{2}$ ) women. Proportional hazards and multiple logistic regression models were applied.

Results: Early pregnancy BMI classified 1246 (66.1\%) women as normal weight, 350 (18.6\%) as overweight and 203 (10.8\%) as obese. No difference in the duration of total or first stage of active labour was found for overweight (adjusted HR $=1.01,95 \% \mathrm{Cl} 0.88-1.16$ ) or obese (adjusted HR $=1.07,95 \% \mathrm{Cl} 0.90-1.28$ ) compared to normal weight women. Median active labour duration was $5.83 \mathrm{~h}$ for normal weight, $6.08 \mathrm{~h}$ for overweight and $5.90 \mathrm{~h}$ for obese women.

The risk of caesarean delivery increased significantly for overweight and obese compared to normal weight women (odds ratios (OR) 1.62; 95\%Cl 1.18-2.22 and 1.76; 95\%Cl 1.20-2.58, respectively). Caesarean deliveries were performed earlier in labour in obese than normal-weight women ( $\mathrm{HR}=1.80,95 \% \mathrm{Cl} 1.28-2.54)$.
\end{abstract}

Conclusion: BMI had no significant effect on total duration of active labour. Risk of caesarean delivery increased with increasing BMI. Caesarean deliveries are undertaken earlier in obese women compared to normal weight women following the onset of active labour, shortening the total duration of active labour.

\section{Background}

Average body mass index (BMI) has increased over the past 30 years and obesity has become a global health issue $[1,2]$. This tendency has a wide range of implications in the field of obstetrics as women with a higher BMI are at risk of various complications during pregnancy such as gestational diabetes, preeclampsia, macrosomia, dystocia, and stillbirths [3, 4]. Furthermore, increasing BMI is associated with an increased rate of caesarean delivery due in part to failure of labourprogression [5-7].

\footnotetext{
* Correspondence: Karen.ellekjaer@gmail.com

'Department of Obstetrics and Gynaecology, Nordsjællands Hospital,

University of Copenhagen, Dyrehavevej 29, 3400 Hillerød, Denmark

Full list of author information is available at the end of the article
}

Previously published studies have not clarified the extent to which BMI influences the duration of labour. One study showed no significant effect [8] whereas others describe prolonged duration of labour with increasing BMI [9-11]. It is pertinent to consider the effect of maternal BMI on the progress and duration of labour in order to facilitate decision-making on potential obstetric interventions. In order to ensure proper labour management, perceptions about labour progression in obese women should be evidence-based and not guided by assumptions.

The objective of this study was to describe the association between BMI during early-pregnancy and the duration of labour. 


\section{Methods}

The study population included women who gave birth at the Department of Gynaecology and Obstetrics, Nordsjællands Hospital, University of Copenhagen, Denmark, between January 1, 2011 and December 31, 2012.

Data were obtained through electronically based hospital charts (Doculive, DLEPR v. 4.9.3.0) describing all prenatal obstetric consultations and ultrasound scans as well as labour, delivery, and the postnatal period. Data were listed according to the Danish 10-digit personal identification number (dd-mm-yy-xxxx).

Data was extracted for women allocated to group 1 or 2 a of Robsons 10 group classification system [12]. Hence, the study population included all nulliparous women with a single cephalic presentation from $370 / 7$ to $426 / 7$ weeks of completed gestation who were either induced or entered labour spontaneously. Multiparous women, multiple pregnancies, pre-term pregnancies, elective caesarean deliveries as well as breeches, transverse- or oblique presentations were excluded. Standard protocol for labour induction in our institution comprised prostaglandininduced cervical ripening or induction with oxytocin. No transcervical catheters were used for induction of labour.

Maternal first trimester height and weight was recorded at the first prenatal consultation. Early pregnancy BMI was calculated and the women were grouped in BMI categories of $<25 \mathrm{~kg} / \mathrm{m}^{2}, 25-29.9 \mathrm{~kg} / \mathrm{m}^{2}$, and $\geq 30 \mathrm{~kg} / \mathrm{m}^{2}$.

Gestational age was assessed with a dating ultrasound scan. Maternal age was calculated from the woman's date of birth. Weight of the baby was recorded after birth. Hypertensive disease was grouped to reflect all women who had hypertensive diseases prior to pregnancy or who developed hypertension or preeclampsia during pregnancy. Manual chart review provided information on smoking status, labour induction, use of cardiotocography (CTG), augmentation using oxytocin, and epidural analgesia.

The primary outcome was duration of active labour. This was recorded as the total duration then subdivided into phases. Total duration of labour was calculated from the beginning of active labour until time of delivery. The beginning of active labour was defined as the onset of regular contractions combined with a dilated cervical orificium $>3 \mathrm{~cm}$. Women who had a cervical orificium dilated further upon arrival at the labour ward were defined as being in active labour from the time of admittance.

The total duration of labour was subdivided into phases 1 and 2. Phase 1 was defined as the period from active labour until the cervix was fully dilated, while phase 2 was defined as the remaining time from full dilatation until birth.

The secondary outcome comprised route of delivery, maternal post-partum complications, neonatal morbidity, and neonatal mortality. Apart from vaginal and caesarean delivery, mode of delivery included the level of urgency for caesarean deliveries. Level 1 required delivery within 15 min compared with 30 min for level 2 and $60 \mathrm{~min}$ for level 3. Maternal post-partum complications comprised post-partum haemorrhage $(\mathrm{PPH})$ with bleeding in excess of $1000 \mathrm{ml}$. A $1000 \mathrm{ml}$ limit for PPH was chosen from a clinical perspective as local protocol requires that women with $\mathrm{PPH}>1000 \mathrm{ml}$ should be referred to an operating theatre in case of a potential need of anaesthesia which is associated with higher risk among obese women. Foetal outcome was assessed by Apgar score at $5 \mathrm{~min}$, arterial cord $\mathrm{pH}$, and admission to the neonatal intensive care unit (NICU).

The study was approved by the Danish Data Protection Agency (case number: HIH-2013-012, I-Suite no: 02208).

\section{Statistical analysis}

Baseline characteristics between the three categories of BMI $\left(<25 \mathrm{~kg} / \mathrm{m}^{2}, 25-29.9 \mathrm{~kg} / \mathrm{m}^{2}\right.$, and $\left.\geq 30 \mathrm{~kg} / \mathrm{m}^{2}\right)$ during early-pregnancy were compared using Chi-squared test. Cox proportional hazards regression was used for analyses regarding duration of labour. Models were fitted with two separate outcome measures. Firstly, an event was defined as vaginal delivery, whereas caesarean delivery was censored. Secondly, an event was defined as caesarean delivery, whereby vaginal birth was the censoring criteria.

Univariate Cox-regression models were performed. In multivariate analyses, adjustments were made for maternal height and age, birth weight, epidural analgesia, induction of labour and administration of oxytocin during labour. In our study we differentiated augmentation with oxytocin from induced labor oxytocin as follows: if oxytocin was administered before the onset of regular contractions in combination with a dilated cervical orifice $>3 \mathrm{~cm}$ it was considered as an attempt at induction. If oxytocin was administered after the onset of regular contractions in combination with a dilated cervical orifice $>3 \mathrm{~cm}$ it was considered as labour augmentation. As all cases were evaluated manually this reduced the risk of incorrect data due to coding errors.- All of the abovementioned factors were chosen due to their independent effect on either labour duration or rates of caesarean delivery. In addition, we wished to adjust for maternal race, however, as this information was not registered in labour charts, we were unable to extract data to include in our mutivariate analysis. Backwards elimination by stepwise regression eliminated hypertensive disease and 
gestational diabetes, which was therefore not accounted for in the final analysis.

Survival curves depicted the number of deliveries over time within each BMI category. The proportional hazard assumption was checked graphically. For the secondary outcome variables, univariate logistic regressions were carried out followed by multivariate analysis, with adjustment for potential confounders. $P$-values $<0.05$ were considered statistically significant.

The database was established using Microsoft Access 2010. Statistical analysis was performed using IBM SPSS Statistics version 19 .

\section{Results}

Data was extracted for a total of 1907 women. Of these, 22 non-Danish citizens were not eligible for inclusion, as they did not possess a permanent Danish personal identification number (CPR), which was necessary for comparable data. Hence, a total of 1885 women were included in the study (Fig. 1).

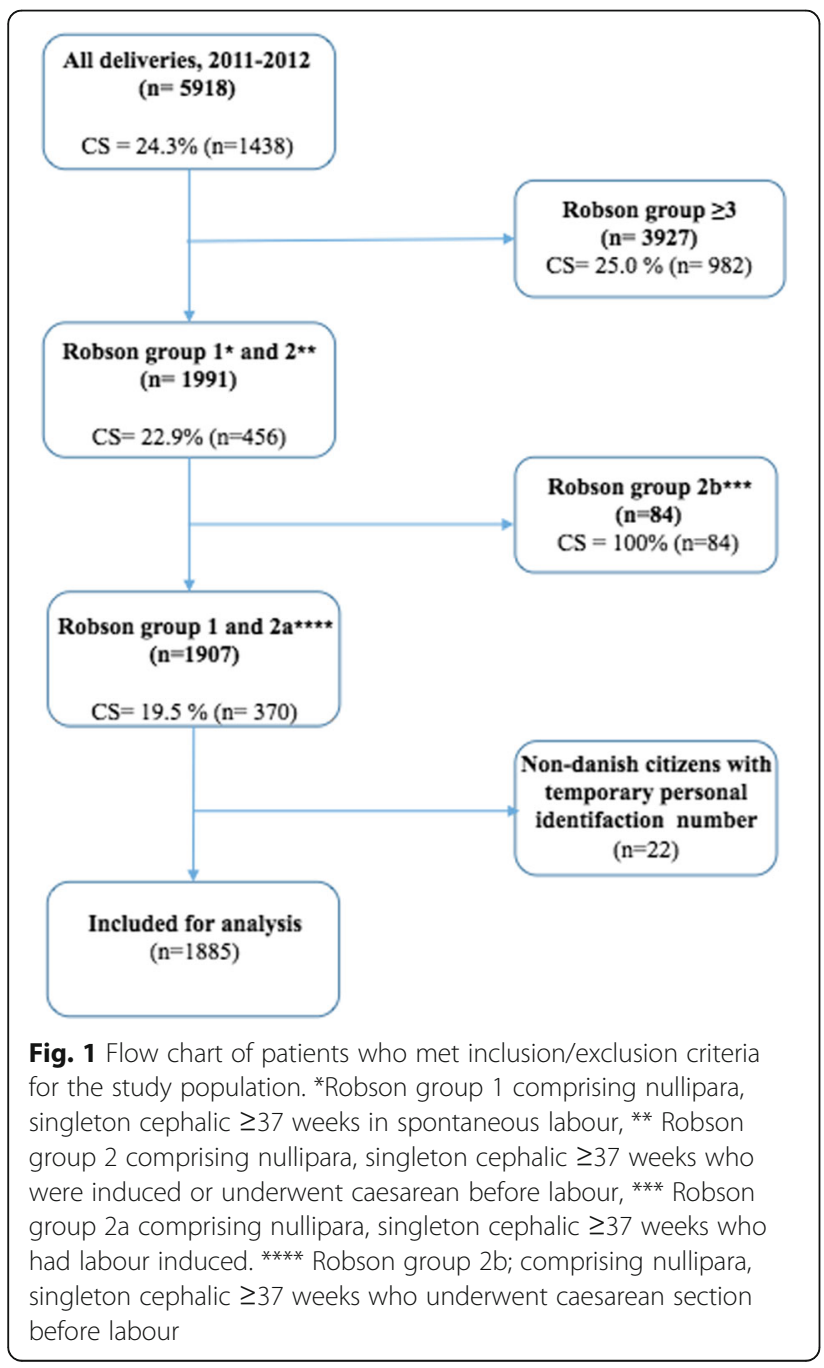

Women of normal weight comprised $66.1 \%$ of the population $(n=1246)$, overweight $18.6 \%(n=350)$, and obese $10.8 \%(n=203)$. Only $4.5 \%(n=86)$ did not have BMI recorded, most often due to lack of attendance at prenatal hospital visits. BMI was equally distributed according to maternal age, height, or gestational age, whereas an association between BMI and hypertensive disease and gestational diabetes was found $(p<0.01)$ (Table 1). The proportion of induced births increased with increasing BMI, as did the use of oxytocin for augmentation of labour, epidural analgesia, and CTG monitoring. Birth weight was associated with BMI.

Labour duration could be determined for 1808 women. Fifty-eight women (3.1\%) had caesarean sections due to a failed attempt of labour induction, whereas 19 women did not have the onset of regular contractions recorded. The number of women who were already in active labour upon admittance to the hospital was equally distributed with regard to BMI $(p=0.09)$. All 1808 women with determined labour duration gave birth within $24 \mathrm{~h}$ of the onset of active labour. Median active labour duration was $5.83 \mathrm{~h}$ for normal weight, $6.08 \mathrm{~h}$ for overweight and $5.90 \mathrm{~h}$ for obese women.

From univariate Cox analysis, we found a hazard ratio (HR) of vaginal delivery of 0.83 (95\% confidence interval [CI] 0.73-0.96) for overweight (BMI 25-29.9 $\mathrm{kg} / \mathrm{m}^{2}$ ) compared to normal weight women, implying a longer duration of active labour for overweight women compared with those with normal-weight (Table 2). However, after adjustment for confounders this association was not significant ( $\mathrm{HR}=1.01,95 \% \mathrm{CI} 0.88-1.16)$. There was no significant difference in total duration of active labour among obese women (BMI $\geq 30 \mathrm{~kg} / \mathrm{m}^{2}$ ) compared to normal weight women, either before or after adjustment for confounders (Fig. 2).

The total duration of labour was subdivided into phases. In total, 155 obese women (76.4\%) reached phase 2 with full dilation of the orifice, whereas the same applied to $284(81.1 \%)$ overweight and $1112(89.2 \%)$ normal weight women $(p<0.01)$ (Table 4$)$. No significant difference in the duration of phase 1 was found between the BMI groups. However, phase 2 showed a more accelerant course of labour in obese than normal weight women, with a HR of 1.29 (95\%CI 1.07-1.55) after adjustment (Table 2).

There were $353(19.5 \%)$ caesarean deliveries in the study popultion comprising 1808 women who had labour duration recorded succesfully. The rate of caesarean deliveries was unequally distributed over the BMI strata, including $16.0 \%(n=199)$ of normal weight, $26.3 \%(n=92)$ of overweight, and $30.5 \%(n=62)$ of obese women being delivered by caesarean $(p<0.01)$. The number of caesarean deliveries was equally distributed between phases 1 and 2 of labour depending on 
Table 1 Distribution of covariates at baseline among women in different body mass index groups

\begin{tabular}{|c|c|c|c|c|}
\hline & & Maternal BMI ${ }^{\mathrm{a}}$ : & & \\
\hline & & $<25$ & $25-29.9$ & $\geq 30$ \\
\hline Covariates & $p$-value & $(n=1246 ; 66.1 \%)$ & $(n=350 ; 18.6 \%)$ & $(n=203 ; 10.8 \%)$ \\
\hline Maternal age & $p=0.92$ & & & \\
\hline$<25$ & & 317 (25.4\%) & $86(24.6 \%)$ & $54(26.6 \%)$ \\
\hline $25-30$ & & 429 (34.4\%) & $126(36.0 \%)$ & $74(36.4 \%)$ \\
\hline $30-35$ & & $376(30.2 \%)$ & $100(28.5 \%)$ & $59(29.1 \%)$ \\
\hline$>35$ & & $124(10.0 \%)$ & $38(10.9 \%)$ & $16(7.9 \%)$ \\
\hline Height & $p=0.75$ & & & \\
\hline$<160 \mathrm{~cm}$ & & $124(10.0 \%)$ & $36(10.3 \%)$ & $15(7.4 \%)$ \\
\hline $160-169 \mathrm{~cm}$ & & $595(47.7 \%)$ & 178 (50.9\%) & $106(52.2 \%)$ \\
\hline $170-179 \mathrm{~cm}$ & & 477 (38.3\%) & $124(35.4 \%)$ & $73(36.0 \%)$ \\
\hline$\geq 180 \mathrm{~cm}$ & & $50(4.0 \%)$ & $12(3.4 \%)$ & $9(4.4 \%)$ \\
\hline Hypertensive disease & $p<0.01$ & & & \\
\hline No & & $1132(90.9 \%)$ & $271(77.4 \%)$ & $158(77.8 \%)$ \\
\hline Yes & & $114(9.1 \%)$ & 79 (22.6\%) & $45(22.2 \%)$ \\
\hline Gestational Diabetes & $p<0.01$ & & & \\
\hline No & & $1218(97.8 \%)$ & 335 (95.7\%) & $188(92.6 \%)$ \\
\hline Yes & & $28(2.2 \%)$ & $15(4.3 \%)$ & $15(7.4 \%)$ \\
\hline Gestational age & $p=0.27$ & & & \\
\hline 37-38 weeks & & $173(13.9 \%)$ & $46(13.1 \%)$ & $36(17.7 \%)$ \\
\hline 39-40 weeks & & $635(51.0 \%)$ & $180(51.4 \%)$ & $98(48.3 \%)$ \\
\hline$\geq 41$ weeks & & 438 (35.1\%) & 124 (35.5\%) & $69(34.0 \%)$ \\
\hline Labour Induced & $p<0.01$ & & & \\
\hline Yes & & $363(29.1 \%)$ & $131(37.4 \%)$ & $98(48.3 \%)$ \\
\hline No & & 831 (70.9\%) & $219(62.6 \%)$ & 105 (51.7\%) \\
\hline CTG & $p<0.01$ & & & \\
\hline Yes & & 906 (72.7\%) & 285 (81.4\%) & $176(86.7 \%)$ \\
\hline No & & $340(27.3 \%)$ & 65 (18.6\%) & 27 (13.3\%) \\
\hline Oxytocin & $p=0.03$ & & & \\
\hline Yes & & 744 (59.7\%) & 232 (66.3\%) & 135 (66.5\%) \\
\hline No & & $502(40.3 \%)$ & 118 (33.7\%) & 68 (33.5\%) \\
\hline Epidural analgesia & $p<0.01$ & & & \\
\hline Yes & & $501(40.2 \%)$ & 170 (48.6\%) & $114(56.2 \%)$ \\
\hline No & & 745 (59.8\%) & 180 (51.4\%) & 89 (43.8\%) \\
\hline Birthweight & $p<0.01$ & & & \\
\hline$<3.0 \mathrm{~kg}$ & & 187 (15.0\%) & 41 (11.7\%) & 11 (5.5\%) \\
\hline $3.0-3.5 \mathrm{~kg}$ & & 439 (35.3\%) & 111 (31.8\%) & 80 (39.8\%) \\
\hline $3.5-4.0 \mathrm{~kg}$ & & $456(36.7 \%)$ & 141 (40.4\%) & $69(34.3 \%)$ \\
\hline$>4.0 \mathrm{~kg}$ & & 162 (13.0\%) & 56 (16.1\%) & 41 (20.4\%) \\
\hline
\end{tabular}

Values are numbers (percentages)

86 women $(4.5 \%)$ did not have BMI recorded and were therefore not accounted for in analysis

BMI $(p=0.30)$. There was no difference in the use of vacuum extraction.

From logistic regression analysis, we found significantly increased odds ratios (OR) of caesarean delivery with increasing $\mathrm{BMI}(\mathrm{OR}=1.62,95 \% \mathrm{CI} 1.18-2.22$ among overweight women and $\mathrm{OR}=1.76$, 95\%CI 1.20 2.58 among obese women versus women of normal weight) (Table 4). Adjustments were made for maternal height and age, birth weight, labour induction, epidural analgesia, and administration of oxytocin during labour. 
Table 2 Cox regression showing the hazard ratio (HR) of vaginal birth in the defined body mass index (BMI) groups, with and without adjustment for covariates

\begin{tabular}{|c|c|c|c|c|}
\hline \multirow[b]{2}{*}{ Covariates } & \multicolumn{4}{|c|}{ Total duration $^{a}$} \\
\hline & Crude HR & $95 \% \mathrm{Cl}$ & Adjusted HR & $95 \% \mathrm{Cl}$ \\
\hline \multicolumn{5}{|l|}{ BMI } \\
\hline$<25$ & 1 & & 1 & \\
\hline $25-29.9$ & 0.83 & [0.73-0.96] & 1.01 & [0.88-1.16] \\
\hline$\geq 30$ & 0.94 & [0.78-1.12] & 1.07 & [0.90-1.28] \\
\hline \multicolumn{5}{|l|}{ Height } \\
\hline$<160 \mathrm{~cm}$ & 1 & & 1 & \\
\hline $160-169 \mathrm{~cm}$ & 1.31 & [1.08-1.59] & 1.32 & [1.09-1.61] \\
\hline $170-179 \mathrm{~cm}$ & 1.44 & [1.18-1.76] & 1.61 & [1.32-1.98] \\
\hline$\geq 180 \mathrm{~cm}$ & 1.66 & [1.21-2.26] & 1.73 & [1.26-2.38] \\
\hline \multicolumn{5}{|l|}{ Age } \\
\hline$<25$ & 1 & & 1 & \\
\hline $25-29$ & 0.87 & [0.77-0.99] & 1.04 & [0.91-1.19] \\
\hline $30-34$ & 0.82 & {$[0.72-0.94]$} & 0.97 & [0.84-1.11] \\
\hline$\geq 35$ & 0.62 & {$[0.51-0.77]$} & 0.68 & [0.54-0.84] \\
\hline \multicolumn{5}{|l|}{ Birthweight } \\
\hline$<3.0 \mathrm{~kg}$ & 1 & & 1 & \\
\hline $3.0-3.5 \mathrm{~kg}$ & 0.77 & [0.66-0.90] & 0.66 & {$[0.56-0.78]$} \\
\hline $3.5-4.0 \mathrm{~kg}$ & 0.53 & {$[0.46-0.62]$} & 0.49 & [0.42-0.58] \\
\hline$>4.0 \mathrm{~kg}$ & 0.38 & {$[0.31-0.46]$} & 0.38 & [0.30-0.47] \\
\hline \multicolumn{5}{|l|}{ Epidural } \\
\hline No & 1 & & 1 & \\
\hline Yes & 0.29 & [0.26-0.32] & 0.33 & [0.29-0.37] \\
\hline
\end{tabular}

Augmentation with oxytocin:

$\begin{array}{lllll}\text { No } & 1 & & 1 & \\ \text { Yes } & 0.31 & {[0.28-0.35]} & 0.40 & \text { [0.36-0.45] } \\ \text { Induced labour: } & & & & \\ \text { No } & 1 & & 1 & \\ \text { Yes } & 0.91 & {[0.82-1.02]} & 1.68 & \text { [1.48-1.90] }\end{array}$

Phase 1

\begin{tabular}{|c|c|c|c|c|}
\hline & Crude HR & $95 \% \mathrm{Cl}$ & Adjusted HR & $95 \% \mathrm{Cl}$ \\
\hline \multicolumn{5}{|l|}{ BMI } \\
\hline$<25$ & 1 & & 1 & \\
\hline $25-29.9$ & 0.99 & [0.86-1.14] & 1.11 & [0.96-1.28] \\
\hline$\geq 30$ & 1.01 & {$[0.85-1.21]$} & 1.04 & [0.86-1.24] \\
\hline
\end{tabular}

Phase 2
Table 2 Cox regression showing the hazard ratio (HR) of vaginal birth in the defined body mass index (BMI) groups, with and without adjustment for covariates (Continued)

\begin{tabular}{|c|c|c|c|c|}
\hline \multicolumn{5}{|l|}{ BMI } \\
\hline$<25$ & 1 & & 1 & \\
\hline $25-29.9$ & 0.90 & [0.96-1.28] & 0.99 & [0.86-1.14] \\
\hline$\geq 30$ & 1.06 & [0.96-1.28] & 1.29 & [1.07-1.55] \\
\hline
\end{tabular}

Phase 1 was defined as the period of time from active labour until the cervix was fully dilated

Phase 2 was defined as the period of time from when the cervix was fully dilated to the actual birth. Caesarean deliveries censored

A hazard ratio (HR) $>1$ indicates an increased number of vaginal deliveries over time compared to the reference group; a shorter duration of labour. A $H R<1$ indicates a decreased number of vaginal deliveries over time compared to the reference group; a longer duration of labour

a 77 women $(4.1 \%)$ did not have duration measures recorded and were therefore not accounted for in analysis

In univariate Cox analysis, we found an increased HR of caesarean delivery, resulting in a shorter duration from onset of active labour until caesarean with increasing BMI. Compared with normal weight women, the HR of caesarean delivery was 1.39 (95\%CI $1.06-1.81)$ for overweight and 1.94 (95\%CI 1.40-2.69) among obese women (Table 3). After adjustment, the results remained significantly increased only for obese women $(H R=1.80$, 95\%CI 1.28-2.54) (Fig. 3).

Post-partum haemorrhage (PPH) occurred in 122 women $(6.5 \%)$. The risk of PPH in the obese women was increased compared with normal weight women $(\mathrm{OR}=2.04,95 \% \mathrm{CI} 1.23-2.38)$. However, after adjustment for birth weight, epidural analgesia, and caesarean delivery, the association was no longer significant $(\mathrm{OR}=1.54,95 \%$ CI $0.90-2.61)$ (Table 4).

There was no difference in neonatal morbidity assessed by Apgar score less than 8 after $5 \mathrm{~min}$ and number of admissions to the NICU according to maternal BMI. However, the incidence of an arterial cord $\mathrm{pH}<7.05$ was $4.3 \%(n=8)$ in the infants of obese women compared with $2.1 \%(n=7)$ in overweight women and $1.6 \%(n=18)$ in normal-weight women $(p=0.04)$. The OR of an arterial cord $\mathrm{pH}<7.05$ within the obese group was increased $(\mathrm{OR}=2.85$, 95\%CI 1.22-6.65) compared with the normal-weight group (Table 4).

One neonatal death occurred in the overweight group.

\section{Discussion}

This retrospective cohort study of nulliparous women demonstrated a slight decrease in labour duration during the second phase of active labour, but not in the total duration of active labour, for obese women compared with normal-weight women. Furthermore, caesarean deliveries were performed sooner in obese women following the onset of active labour than in 


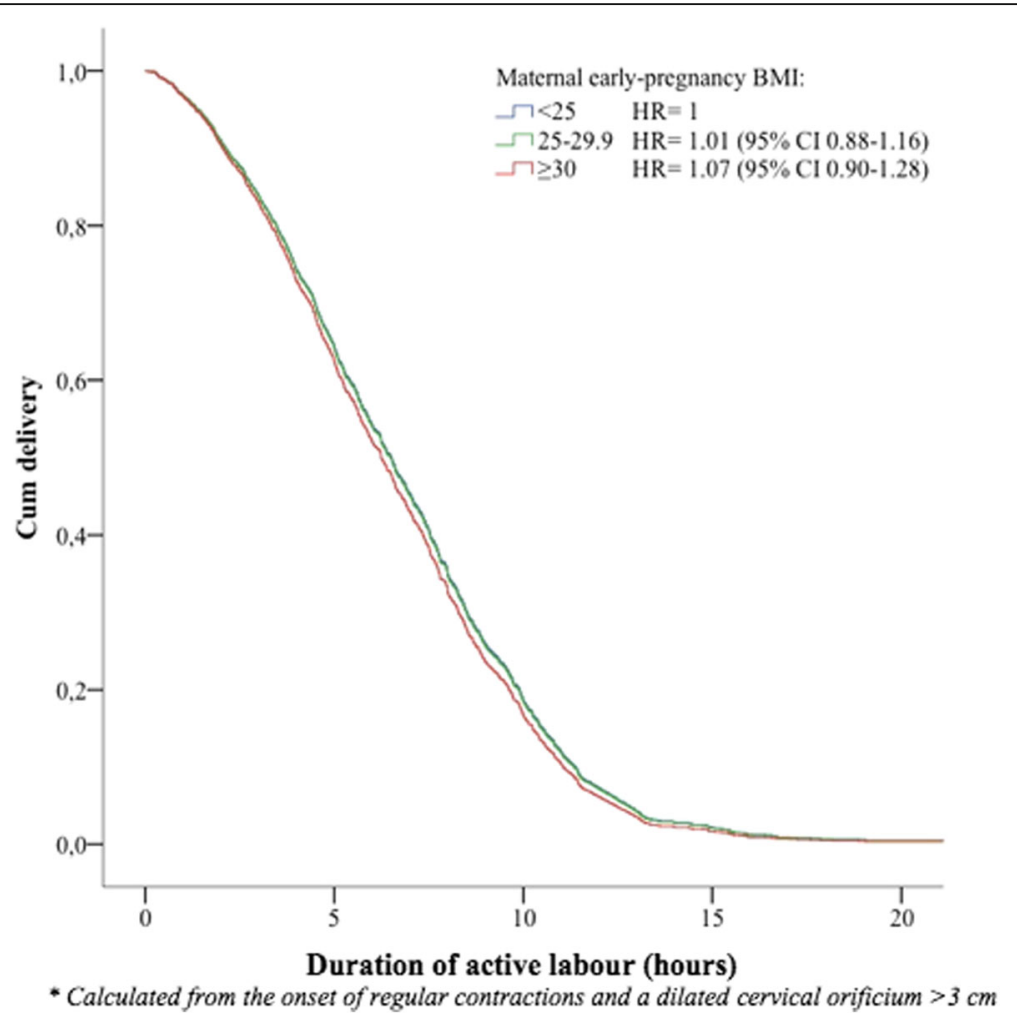

Fig. 2 Survival plot as a function of time from onset of active labour until vaginal delivery. Event was defined as delivery. Women were censored at the time of caesarean delivery. Adjustments were made for maternal age, height, birth weight, labour induction, augmentation with oxytocin, and epidural analgesia. A hazard ratio $(H R)>1$ illustrates a shorter duration of labour while a $H R<1$ illustrates a longer duration of labour compared to the reference group consisting of normal-weight women

normal-weight women undergoing caesarean, thereby shortening the total duration of active labour in obese women.

A few previous studies suggested no association between labour progression and increasing BMI. A British study of 8350 nulliparous women compared labour progression in obese versus non-obese women, observing no significant difference within the first or second stages of labour [8]. Contrary to our findings, a majority of previous studies report an independent effect of BMI on total duration of active labour. These studies specifically identify the duration of the first stage of labour as being increased, further supporting an overall increase in labour duration [9-11, 13-15]. A study by Kominiarek et al. included 118,978 nulli- and multiparous women in separate analyses. This study found a significant increase in total duration of labour with increasing BMI among nulliparous women [11]. However, the definition of active labour differed from that of most other studies, as a cervical dilatation of only $1 \mathrm{~cm}$ was accepted when defining the onset of labour, thereby including what was considered as the latent phase in the current study.
A study by Carlhäll et al. included 63,829 nulliparous women and found a significantly slower progression of labour but reduced duration of the second stage of labour in obese women compared with women with normal BMI [9]. The latter finding is in agreement with that of our study. However, their definition of the second stage of labour was confined to the initiation of pushing efforts and can therefore not be directly compared to the results of our study, as we defined the second stage of labour as the time when the cervical orificium was fully dilated. In contrast to our study, Carlhäll et al. did not include augmentation by oxytocin and the use of epidural analgesia as confounders. Because these parameters have an independent effect on the duration of labour [16] and both appear to be unequally distributed with regard to BMI, this could possibly have distorted the outcomes.

A greater number of censored cases within the obese group during the second stage of labour could have explained our findings of a decreased duration of phase 2 . However, this was not the case because caesarean deliveries were less frequently performed in obese women after entering the second stage of labour compared to women of normal BMI. Nevertheless, fewer obese 
Table 3 Cox regression showing the hazard ratio $(H R)$ of caesarean delivery comparing the defined BMI groups, with and without adjustment for covariates

\begin{tabular}{|c|c|c|c|c|}
\hline \multirow[b]{2}{*}{ Covariates } & \multicolumn{4}{|c|}{ Total labour ${ }^{a}$} \\
\hline & Crude HR & $95 \% \mathrm{Cl}$ & Adjusted HR & $95 \% \mathrm{Cl}$ \\
\hline \multicolumn{5}{|l|}{$\mathrm{BMI}$} \\
\hline$<25$ & 1 & & 1 & \\
\hline $25-29.9$ & 1.39 & {$[1.06-1.81]$} & 1.28 & [0.97-1.69] \\
\hline$\geq 30$ & 1.94 & [1.40-2.69] & 1.80 & {$[1.28-2.54]$} \\
\hline \multicolumn{5}{|l|}{ Height } \\
\hline$<160 \mathrm{~cm}$ & 1 & & 1 & \\
\hline $160-169 \mathrm{~cm}$ & 0.83 & [0.60-1.15] & 0.77 & [0.55-1.09] \\
\hline $170-179 \mathrm{~cm}$ & 0.74 & [0.52-1.05] & 0.64 & [0.44-0.93] \\
\hline$\geq 180 \mathrm{~cm}$ & 0.67 & {$[0.31-1.41]$} & 0.50 & [0.23-1.08] \\
\hline \multicolumn{5}{|l|}{ Age } \\
\hline$<25$ & 1 & & 1 & \\
\hline $25-29$ & 0.99 & {$[0.72-1.37]$} & 0.97 & [0.69-1.37] \\
\hline $30-34$ & 1.22 & [0.88-1.68] & 1.31 & [0.94-1.84] \\
\hline$\geq 35$ & 1.57 & [1.08-2.29] & 1.82 & [1.22-2.69] \\
\hline \multicolumn{5}{|l|}{ Birthweight } \\
\hline$<3.0 \mathrm{~kg}$ & 1 & & 1 & \\
\hline $3.0-3.5 \mathrm{~kg}$ & 0.89 & {$[0.56-1.41]$} & 0.98 & [0.59-1.61] \\
\hline $3.5-4.0 \mathrm{~kg}$ & 1.03 & [0.67-1.59] & 1.13 & {$[0.71-1.82]$} \\
\hline$>4.0 \mathrm{~kg}$ & 1.39 & [0.87-2.18] & 1.43 & {$[0.87-2.36]$} \\
\hline \multicolumn{5}{|l|}{ Epidural } \\
\hline No & 1 & & 1 & \\
\hline Yes & 1.16 & [0.88-1.53] & 0.96 & [0.72-1.29] \\
\hline
\end{tabular}

Augmentation with oxytocin

$\begin{array}{cllll}\text { No } & 1 & & 1 & \\ \text { Yes } & 1.21 & {[0.85-1.72]} & 0.96 & \text { [0.65-1.42] } \\ \text { Induced labour } & & & & \\ \text { No } & 1 & & 1 & \\ \text { Yes } & 1.80 & {[1.43-2.27]} & 1.67 & {[1.33-2.17]}\end{array}$

Phase 1

$\begin{array}{lllll} & \text { Crude HR } & 95 \% \mathrm{Cl} & \text { Adjusted HR } & 95 \% \mathrm{Cl} \\ \text { BMI } & & & & \\ <25 & 1 & & 1 & \\ 25-29.9 & 1.68 & {[1.07-2.66]} & 1.55 & {[0.97-2.48]} \\ \geq 30 & 1.56 & {[0.86-2.84]} & 1.56 & {[0.84-2.89]}\end{array}$

Phase 2
Table 3 Cox regression showing the hazard ratio (HR) of caesarean delivery comparing the defined BMI groups, with and without adjustment for covariates (Continued)

\begin{tabular}{|c|c|c|c|c|}
\hline \multicolumn{5}{|l|}{ BMl } \\
\hline$<25$ & 1 & & 1 & \\
\hline $25-29.9$ & 1.22 & [0.77-1.94] & 1.08 & {$[0.67-1.74]$} \\
\hline$\geq 30$ & 1.56 & {$[0.86-2.84]$} & 1.56 & [0.84-2.89] \\
\hline \multicolumn{5}{|c|}{$\begin{array}{l}\text { Phase } 1 \text { defined as the period of time from active labour until fully dilated } \\
\text { Phase } 2 \text { defined as the period of time from when fully dilated until actual } \\
\text { birth. Vaginal deliveries censored } \\
\text { A HR }>1 \text { illustrates an increased number of caesarean deliveries over time } \\
\text { compared to the reference group; A shorter duration of labour. A HR }<1 \\
\text { illustrates a decreased number of vaginal deliveries over time compared to } \\
\text { the reference group; A longer duration of labour } \\
\text { a77 women (4.1\%) did not have duration measures recorded and were } \\
\text { therefore not accounted for in analysis }\end{array}$} \\
\hline
\end{tabular}

women entered the second stage of labour compared with women of normal weight, thus decreasing the number of women available for the analysis.

We found a significant increase in caesarean deliveries with increasing BMI. This is in accordance with the findings of several larger studies [3-5]. A review by Wispelwey et al. summarized the main risk modulators of caesarean delivery in obese women, including difficulty in initiation of labour and increased induction rates [17]. Since our study only describes women who initiated active labour, and we adjusted for medical induction in statistical analyses it seems likely that there is an independent effect of obesity on the risk of caesarean delivery.

We found that obese women were granted fewer hours of active labour before a caesarean was performed compared with women of normal weight. This could be explained by a possible earlier onset of labour complications within the obese population. However, since there was no difference in the numbers within the different levels of emergency caesareans, this seems unlikely (data not shown). Alternatively, an increased consciousness amongst healthcare staff concerning the issue of maternal obesity may have had an indirect influence on treatment. A more cautious approach to managing these women might have been unknowingly adopted, resulting in an earlier decision to perform a caesarean delivery [18].

The occurrence of $\mathrm{PPH}>1000 \mathrm{~mL}$ was associated with increasing early-pregnancy BMI. In multiple logistic regression analyses, the association was no longer significant, but the estimate still indicated an increased risk of PPH with higher BMI. Accordingly, most other studies found an isolated effect of obesity on the risk of PPH [19].

A slight increase in the incidence of arterial cord $\mathrm{pH}$ values $<7.05$ was associated with increasing earlypregnancy BMI, which could indicate a neonatal 


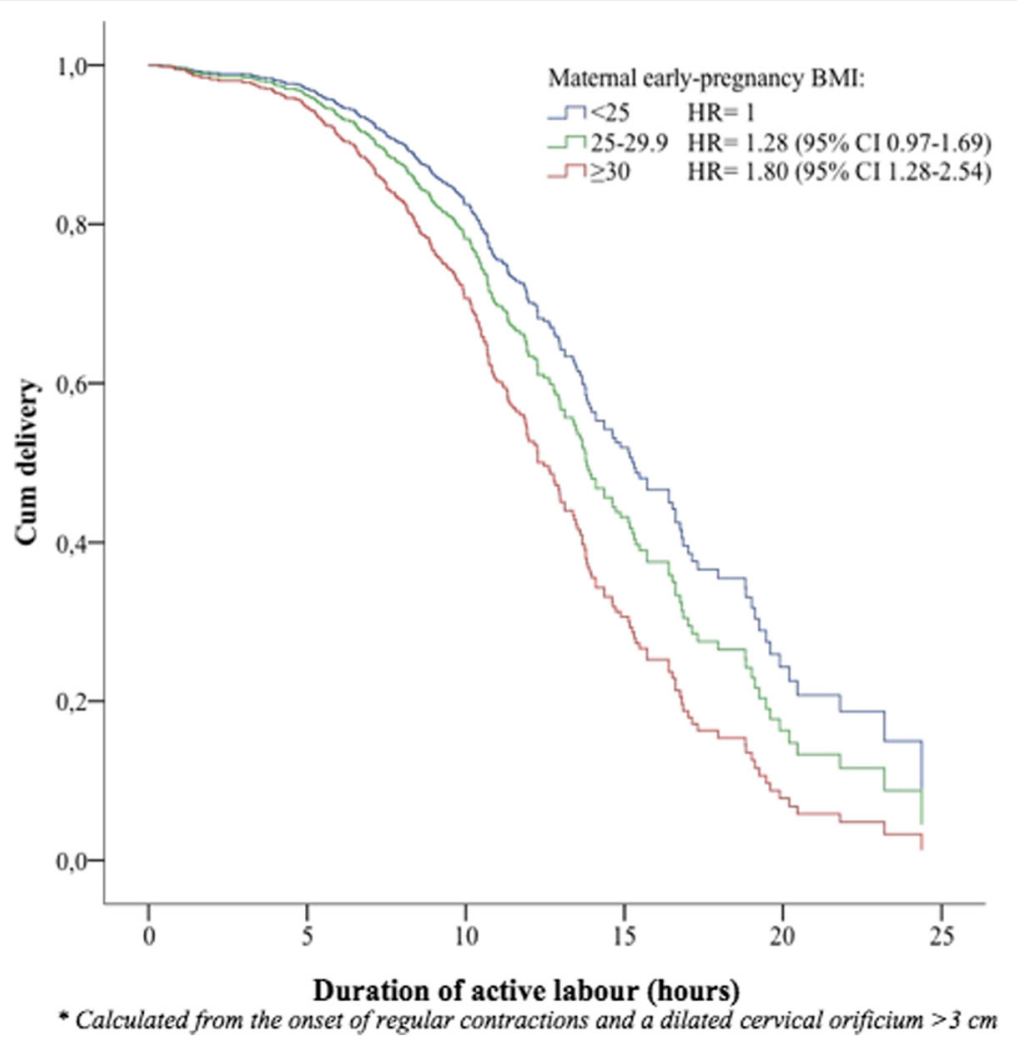

Fig. 3 Survival plot as a function of time from the onset of active labour until caesarean delivery. Event was defined as delivery. Women were censored at the time of vaginal delivery. Adjustments were made for maternal age, height, birth weight, labour induction, augmentation with oxytocin, and epidural analgesia. A hazard ratio $(H R)>1$ illustrates a shorter duration of labour while a HR $<1$ illustrates a longer duration of labour compared to the reference group consisting of normal-weight women

outcome that was less positive [20]. The remaining foetal outcome measurements were not associated with maternal BMI.

\section{Conclusion}

We found no association between BMI and the total duration of labour; however, an increased risk of a shorter second stage of labour was apparent for obese women. Our results suggest an overall increased risk of caesarean delivery with increasing BMI. Furthermore, caesarean deliveries performed on obese women were carried out earlier in the course of labour, giving obese women a shorter time of active labour compared with normal-weight women delivering by caesarean.

The risk of PPH in excess of $1000 \mathrm{~mL}$ increased with increasing BMI, but only in unadjusted analysis. Additionally, an increased risk of arterial cord blood with $\mathrm{pH}$ $<7.05$ was identified. The remaining neonatal outcome measures were unaffected by BMI.

The results of this study provide valuable information on the expected progression of labour in overweight and obese women and should aid obstetric care providers in deciding if and when to intervene in the labour process. Defining the normal progression of labour for overweight and obese women can help eradicate nonscientific misconceptions about the influence of obesity, resulting in more appropriate treatment of women in this weight group. Finally, the results will aid obstetric health care providers in counselling women on the effect of their overweight.

\section{Strengths}

- Consecutive sampling of women over a 2-year period reduces the selection bias of the cohort

- The sampling of data reveals results that depict everyday practice.

- All charts were manually scrutinized and data for all variables were validated, enhancing the quality of our data

- Adjustments for multiple important confounders were performed.

\section{Limitations}

- The size of the study population.

- BMI was recorded in early pregnancy and this study can therefore not account for the effect of 
Table 4 Descriptive and logistic regression analysis regarding secondary outcome variables. Values of odds ratios are presented as crude estimates as well as after adjustment

\begin{tabular}{|c|c|c|c|c|c|c|c|}
\hline Secondary outcome variables & $p$-value & & & Crude OR & $95 \% \mathrm{Cl}$ & Adjusted OR & $95 \% \mathrm{Cl}$ \\
\hline Total number of caesarean deliveries $^{a}$ & $(p<0.01)$ & No & Yes & & & & \\
\hline $\mathrm{BMI}<25$ & & 1047 (84.0\%) & $199(16.0 \%)$ & 1 & & 1 & \\
\hline BMI 25-29.9 & & $258(73.7 \%)$ & $92(26.3 \%)$ & 1.88 & [1.42-2.49] & 1.62 & {$[1.18-2.22]$} \\
\hline $\mathrm{BMI} \geq 30$ & & $141(69.5 \%)$ & $62(30.5 \%)$ & 2.31 & {$[1.66-3.23]$} & 1.76 & {$[1.20-2.58]$} \\
\hline Caesarean prior to onset of active labor ${ }^{a}$ & $(p<0.01)$ & No & Yes & & & & \\
\hline $\mathrm{BMI}<25$ & & $22(1.8 \%)$ & $1211(98.2 \%)$ & 1 & & 1 & \\
\hline BMI 25-29.9 & & $19(5.4 \%)$ & $331(94.6 \%)$ & 1.99 & {$[1.12-3.52]$} & 1.64 & {$[0.90-2.98]$} \\
\hline $\mathrm{BMI} \geq 30$ & & $18(8.9 \%)$ & $185(91.1 \%)$ & 3.37 & {$[1.87-6.07]$} & 2.75 & {$[1.47-5.16]$} \\
\hline Reached 2nd stage of labour ${ }^{a}$ & $(p<0.01)$ & No & Yes & & & & \\
\hline $\mathrm{BMI}<25$ & & $134(10.8 \%)$ & $1112(89.2 \%)$ & 1 & & 1 & \\
\hline BMI 25-29.9 & & $66(18.9 \%)$ & $284(81.1 \%)$ & 1.85 & {$[1.38-2.48]$} & 0.61 & {$[0.45-0.84]$} \\
\hline $\mathrm{BMI} \geq 30$ & & $48(23.6 \%)$ & $155(76.4 \%)$ & 2.13 & {$[1.50-3.03]$} & 0.59 & {$[0.40-0.85]$} \\
\hline Vacuum delivery ${ }^{\mathrm{b}}$ & $(p=0.39)$ & No & Yes & & & & \\
\hline $\mathrm{BMI}<25$ & & 1068 (85.7\%) & $178(14.3 \%)$ & 1 & & 1 & \\
\hline BMI 25-29.9 & & $304(86.9 \%)$ & $46(13.1 \%)$ & 0.91 & {$[0.64-1.27]$} & 0.83 & {$[0.58-1.18]$} \\
\hline $\mathrm{BMI} \geq 30$ & & $181(89.2 \%)$ & $22(10.8 \%)$ & 0.73 & {$[0.46-1.17]$} & 0.65 & {$[0.40-1.06]$} \\
\hline Post-partum haemorrhage $\geq 1000 \mathrm{~mL}^{c}$ & $(p=0.02)$ & No & Yes & & & & \\
\hline $\mathrm{BMI}<25$ & & $1176(89.1 \%)$ & $70(10.9 \%)$ & 1 & & 1 & \\
\hline BMI 25-29.9 & & $325(92.9 \%)$ & $25(7.1 \%)$ & 1.29 & {$[0.81-2.07]$} & 1.04 & {$[0.64-1.70]$} \\
\hline $\mathrm{BMI} \geq 30$ & & $181(89.2 \%)$ & $22(10.8 \%)$ & 2.04 & {$[1.23-3.38]$} & 1.54 & {$[0.90-2.61]$} \\
\hline Arterial cord $\mathrm{pH}<7.05^{\mathrm{d}}$ & $(p=0.04)$ & No & Yes & & & & \\
\hline $\mathrm{BMI}<25$ & & $1128(98.4 \%)$ & $18(1.6 \%)$ & 1 & & & \\
\hline BMI 25-29.9 & & $323(97.9 \%)$ & $7(2.1 \%)$ & 1.36 & {$[0.56-3.28]$} & & \\
\hline $\mathrm{BMI} \geq 30$ & & $187(95.7 \%)$ & $8(4.3 \%)$ & 2.85 & {$[1.22-6.65]$} & & \\
\hline
\end{tabular}

${ }^{a}$ Adjustments made for: Age, height, birthweight, labour induction, epidural analgesia and use of oxytocin during labour

${ }^{\mathrm{b}}$ Adjustments made for: Age and use of oxytocin during labour

${ }^{c}$ Adjustments made for: Birthweight, epidural analgesia and caesarean delivery

${ }^{\mathrm{d}}$ No Adjustments were made

gestational weight gain on labour duration or outcome.

- Gestational age at the first prenatal visit was not recorded; however, most women attended visits early in their pregnancy, as is standard practice

- Measurements of cervical dilation were subjective and were based on examinations performed by numerous midwives

- The results of this study are only applicable to women who reach the active stage of labour as it does not take into consideration the duration of the preliminary latent phase.

- The uniformity of labour management cannot be ensured due to the number of different care providers. However, all personnel are required to follow established guidelines, which should eliminate any substantial differences in the management of care

\section{Abbreviations}

BMI: Body mass index; Cl: Confidence interval; CTG: Cartiotocography; HR: Hazard ratio; NICU: Neonatal intensive care unit; OR: Odss ratio; PPH: Post partum haemorrhage

\section{Acknowledgments}

A special thanks to Dr. Jørgen G. Berthelsen, Nordsjællands Hospital, for providing data extracts.

\section{Funding}

This work was supported by "The Research Fund", Nordsjællands Hospital, University of Copenhagen. The funding sources had no involvement in any part of this study.

\section{Availability of data and materials}

The datasets used and/or analysed during the current study available from the corresponding author on reasonable request.

\section{Authors' contributions}

KLE has made substantial contributions to the conception, design of the work, the acquisition, the analysis and the interpretation of data for the work. KLE has drafted the work and approved the final version to be published. EL, TB has made substantial contributions to the conception, the design of the work and the interpretation of data for the work. EL has critically revised the work for important intellectual content and approved 
of the final version to be published. TB has critically revised the work for important intellectual content and approved of the final version to be published. KLE, EL, TB agree to be accountable for all aspects of the work in ensuring that questions related to the accuracy or integrity of any part of the work are appropriately investigated and resolved. All authors read and approved the final manuscript.

\section{Ethics approval and consent to participate}

The study was approved by the Danish Data Protection Agency (case number: HIH-2013-012, I-Suite no: 02208). Date of approval March 16, 2013. The need for consent has been waived as it is deemed unnecessary according to national regulations.

\section{Consent for publication}

Not applicable.

\section{Competing interests}

The authors declare that they have no competing interests.

\section{Publisher's Note}

Springer Nature remains neutral with regard to jurisdictional claims in published maps and institutional affiliations.

\section{Source of study}

Department of Obstetrics and Gynaecology, Nordsjællands Hospital, University of Copenhagen, Denmark.

\section{Author details}

'Department of Obstetrics and Gynaecology, Nordsjællands Hospital, University of Copenhagen, Dyrehavevej 29, 3400 Hillerød, Denmark. ${ }^{2}$ Department of Obstetrics and Gynaecology, Rigshospitalet, University of Copenhagen, Blegdamsvej 9, 2100 Copenhagen, Denmark.

Received: 11 January 2017 Accepted: 5 July 2017

Published online: 12 July 2017

\section{References}

1. World Health Organization. Global Health Observatory Data Repository. Available at: http://apps.who.int/gho/data/node.main.A903?lang=en. Accessed 6 Nov 2014.

2. Fisher SC, Kim SY, Sharma AJ, Rochat R, Morrow B. Is obesity still increasing among pregnant women? Prepregnancy obesity trends in 20 states, 20032009. Prev Med. 2013;56:372-8.

3. Cedergren MI. Maternal morbid obesity and the risk of adverse pregnancy outcome. Obstet Gynecol. 2004;103:219-24.

4. Davies GA, Maxwell C, McLeod L, Gagnon R, Basso M, Bos H, et. al. Obesity in pregnancy. J Obstet Gynaecol Can 2010;32:165-173.

5. Bergholt T, Lim LK, Jorgensen JS, Robson MS. Maternal body mass index in the first trimester and risk of caesarean delivery in nulliparous women in spontaneous labour. Am J Obstet Gynecol. 2007;196:163.e1-5.

6. Poobalan AS, Aucott LS, Gurung T, Smith WC, Bhattacharya S. Obesity as an independent risk factor for elective and emergency delivery in nulliparous women-systematic review and meta-analysis of cohort studies. Obes Rev. 2009;10:28-35

7. Cedergren MI. Non-elective caesarean delivery due to ineffective uterine contractility or due to obstructed labour in relation to maternal body mass index. Eur J Obstet Gynecol Reprod Biol. 2009:145:163-6.

8. Usha Kiran TS, Hemmadi S, Bethel J, Evans J. Outcome of pregnancy in a woman with an increased body mass index. BJOG. 2005;112:768-72.

9. Carlhall S, Kallen K, Blomberg M. Maternal body mass index and duration of labour. Eur J Obstet Gynecol Reprod Biol. 2013;171:49-53.

10. Norman SM, Tuuli MG, Odibo AO, Caughey AB, Roehl KA, Cahill AG. The effects of obesity on the first stage of labour. Obstet Gynecol. 2012;120: $130-5$.

11. Kominiarek MA, Zhang J, Vanveldhuisen P, Troendle J, Beaver J, Hibbard JU. Contemporary labour patterns: the impact of maternal body mass index. Am J Obstet Gynecol. 2011;205:244.e1-8.

12. Robson MS. Can we reduce the caesarean section rate? Best Practice Res Clin Obstet Gynaecol. 2001;15(1):179-94.
13. Vahratian A, Zhang J, Troendle JF, Savitz DA, Siega-Riz AM. Materna prepregnancy overweight and obesity and the pattern of labour progression in term nulliparous women. Obstet Gynecol. 2004;104:943-51.

14. Hilliard AM, Chauhan SP, Zhao Y, Rankins NC. Effect of obesity on length of labour in nulliparous women. Am J Perinatol. 2012;29:127-32.

15. Pevzner $L$, Powers BL, Rayburn WF, Rumney P, Wing DA. Effects of maternal obesity on duration and outcomes of prostaglandin cervical ripening and labour induction. Obstet Gynecol. 2009;114:1315-21.

16. Anim-Somuah M, Smyth RM, Jones L. Epidural versus non-epidural or no analgesia in labour. Cochrane Database Syst Rev. 2011;(12):CD000331.

17. Wispelwey BP, Sheiner E. Cesarean delivery in obese women: a comprehensive review. J Matern Fetal Neonatal Med. 2013;26(6):547-51. doi:10.3109/14767058.2012.745506

18. Foy AJ, Filippone EJ. The case for intervention bias in the practice of medicine. Yale J Biol Med. 2013:86(2):271-80.

19. Blomberg M. Maternal obesity and risk of postpartum haemorrhage. Obstet Gynecol. 2011:118:561-8.

20. Malin GL, Morris RK, Khan KS. Strength of association between umbilical cord $\mathrm{pH}$ and perinatal and long term outcomes: systematic review and meta-analysis. BMJ. 2010;340:c1471.

\section{Submit your next manuscript to BioMed Central and we will help you at every step:}

- We accept pre-submission inquiries

- Our selector tool helps you to find the most relevant journal

- We provide round the clock customer support

- Convenient online submission

- Thorough peer review

- Inclusion in PubMed and all major indexing services

- Maximum visibility for your research

Submit your manuscript at www.biomedcentral.com/submit 